\title{
FRUITY BATIDAS: \\ The Technologies and Aesthetics of Kuduro \\ Feature Article
}

GARTH SHERIDAN

RMIT UNIVERSITY (AUSTRALIA)

\begin{abstract}
The interconnectedness of music technologies, studio innovation and dancing bodies is a key feature of electronic music cultures. An emerging scholarship by writers such as Butler and Tjora has bridged these studio and performance spaces, revealing the relationship between machine, music and party. This article considers the centrality of studio and performance technologies and techniques in the developing aesthetics of kuduro, a hybrid musical genre that draws on house, techno, soca and regional styles. I use interviews and observation of studio and performance practices to illustrate shifts within the genre and examine musical examples to highlight transitions. I argue that the increased availability of digital musical technologies in Angola shaped the development of kuduro through the 1990s and into the 2000s. Furthermore, I argue that kuduro producers and performers have developed a range of aesthetic and performative practices that reflect material, technological and social restraints common to life in contemporary Angola. By examining interviews with kuduro practitioners and musical examples, this article sheds new light on the under examined aesthetics of kuduro.
\end{abstract}

KEYWORDS: kuduro, hybridity, aesthetics, lusophone, technology, studio practice

GARTH SHERIDAN is a PhD candidate at RMIT University. He has further publications on kuduro forthcoming. Garth has produced various forms of electronic music, including kuduro, under the moniker unsoundbwoy. Email: <garth.sheridan@rmit.edu.au>

Dancecult: Journal of Electronic Dance Music Culture 6(1): 83-96 ISSN 1947-5403 @2014 Dancecult http://dj.dancecult.net DOI 10.12801/1947-5403.2014.06.01.05 


\section{INTRODUCTION}

The use of aesthetics has been established since the 1980s as an analytical tool for the discussion of popular music. While a body of scholarship that discusses electronic dance music (EDM) cultures in these terms is emerging, the musical output of communities outside of North America and Europe require more scholarly attention. Kuduro is an electronic music and dance style that developed in Angola through the 1990s. Kuduro music and dance are hybrid styles that draw on local and global influences and filter these sounds and movements through personal and collective experiences, leaving sonic and gestural residues. While musicians in Portugal and beyond began to DJ, compose and innovate kuduro, this article will focus on the centrality of studio and performance technologies and techniques in Angolan kuduro.

As kuduro developed in the 1990s, Angola experienced periods of war, repression and occasional phases of relative calm. The producers, vocalists, DJs and dancers that created and performed kuduro lived in a nation that was either at war or under the post-war authoritarian government. The experiences of social upheaval resulting from the war have shaped the music. Following anti-colonial resistance and the Portuguese Revolution, the colonial government was forced to relinquish control to a local transitional government. Power struggles within the transitional government led to the Angolan Civil War shortly after Portuguese withdrawal. The war became a flashpoint for Cold War politics as the independence movement fractured. While the two major parties both espoused socialist rhetoric, they formed allegiances with opposing Cold War powers. The People's Movement for the Liberation of Angola (MPLA) received economic, military and social assistance from Cuba, while The National Union for the Total Independence of Angola (UNITA) received support from South Africa and the United States. The struggle between MPLA and UNITA would go on to outlive the struggle between the Soviet Union and the USA. The displacement of millions of rural Angolans during the Civil War and the ongoing lack of political, social and economic inequality under MPLA rule continue to shape Angola. As the war drew to a close, popular forms of music and dance, including kuduro, became important channels for national healing and the development of post-war individual and collective identity. Alisch and Siegert (2011) have argued that a two-way relationship between kuduro and Angolan identity is evident. Kuduro practitioners also have this perspective. MC Sacerdote suggests, "kuduro is really influenced by the energy of the Angolan nation", ${ }^{1}$ while Coréon Du has argued further, "the Angolanness in kuduro is one that subverts stereotypes of Africanness expected by the Western mind" (dos Santos 2012).

By the late 1980s, clubs in Luanda were playing techno and house alongside American pop music and locally produced genres including kizomba and zouk. Cyclic patterns of immigration of middle-class ${ }^{2}$ Angolan youth between Portugal and Angola increased the availability of imported music and musical instruments. As Angola transitioned toward a multi-party political system in the early 1990s, a number of short-lived ceasefires came into effect, and a range of newly available music inspired youth. This included recordings 
available from street-side markets, local parties and club nights, and raves in Europe for those with international mobility. As this music became available, Angolan youths began to make electronic music. These early compositions became known as batida, a genre that utilised house and soca rhythms. Batida translates to "beats" in English and, though the genre is less common now, the term batida is still used to refer to the instrumental component of kuduro tracks. Batida gradually developed into kuduro as the tempo increased, incorporating regional rhythms and sounds. Kuduro became the soundtrack to the last years of the Civil War. The lyrical content of many early kuduro tracks reflects hope for the future of Angola and the development of a less fractured national identity. As Angola was de-militarising in 1997, Tvedten argued that "expectations of what civilian life will bring are high and clearly unrealistic" and that "disillusioned, demobilized soldiers already represent a threat in many communities" (1997: 109). The hope that Tvedten recognises dwindled as the MPLA consolidated political power, cancelled democratic elections and resumed war with UNITA. As discussed by Krug (2011) and Moorman (2008a), popular musicians were co-opted by government and military figures for political purposes. Young working-class Luandans took kuduro and began making a harder and faster interpretation of the genre with lyrics that reflected and connected with experiences of life in the musseques (Luanda's informal, unpaved and marginal neighbourhoods).

This article details how the emergent practices and technologies have impacted the development of kuduro, and argues for a relationship between these developments and the expressive intent of the music. I show ways that the genre and its aesthetic qualities can be seen as a response to globalisation. I describe the compositional processes of kuduro and look at the role of studio technologies in the development of kuduro's aesthetics from the 1990 s to the present. Through discussion of musical practices, the article highlights creative and expressive ways that predominantly self-taught producers have used limited production and communication technologies to create and share music. While musical practice is the central focus of this article, compositional processes and technologies are discussed in the context of Angola's developing political, social and cultural landscape. By providing this context, I present the evolution of kuduro as a response to local, domestic and international politics, including the personal and collective experience of post-war reconstruction.

\section{SCOPE AND Methodology}

Kuduro itself is an emerging subject of enquiry, with little material published at this time. Works on this subject have tended to focus on social practices and contexts of the genre, including the potential for kuduro as an element of collective trauma recovery (Alisch and Siegert 2013), kuduro as utopianism (Brown 2011), government intervention (Moorman $2008 \mathrm{~b}$ ), and the ongoing relevance of lusotropicalismo (Krug 2011). ${ }^{3}$ While musical practice is the central theme of this article, I will nevertheless consider social context, and engage with the developing discourse on kuduro. The international consumption of kuduro within a "global bass" ${ }^{4}$ context highlights that kuduro is one of many electronic music genres produced in the global South. Discourse surrounding global bass genres such as nortek 
(Madrid 2008), kwaito (Steingo 2005), and reggaeton (Rivera et al 2009) provide a broader and more established critical field. This body of work has shown how listeners interpret meanings and messages from music that is criticised for being vapid or without aesthetic value (Dennis 2010). In addition to context provided by global bass, kuduro's situation within the broader frame of EDM provides insight into issues such as the role of technology in developing genres (Sicko 2010), studio and performance practices (Butler 2006), and imaginative and transgressive ways musicians can repurpose technology (Tjora 2009). While experienced internationally within diasporic communities and niche subcultures, kuduro is currently the most popular music in Angola, finding listeners across a wide range of age and social groups. Discussions on the role of the aesthetics of popular music (Gracyk 1996) and rock music (Wicke 1990) in shaping social interaction and subcultural values further inform this work.

The article builds on field-based research conducted in Angola and Portugal in 2012. I travelled to Luanda for the first International Conference on Kuduro, an interdisciplinary conference attended by local and international practitioners, academics and cultural figures. The central theme of the conference was how technology, global citizenship, intercultural commmunication and exchange impacted on the genesis and performance of kuduro. Conducting fieldwork, I interviewed kuduro producers, vocalists and dancers. Participants were recruited partly through an open call out during the conference, while others were approached through established networks. Utilising participant observation methods, I attended a range of events from small club nights through to larger scale outdoor events, including the career celebration for Fofando. I also employed practice-based research through studio collaboration, improvisational location recording and performance as a DJ for live vocal acts. The collaborative approach was integral to its usefulness as a research methodology in this instance, as a wide range of processes, issues and the usage of technologies could be discussed whilst composing or recording.

\section{Studio Practices}

There are three generations of kuduro practitioners that have each lasted roughly a decade. The first generation of kuduro producers is predominantly comprised of middle-class youth and includes Sebem, Rei Helder and Tony Amado. Second-generation artists including Os Lambas, Fofando and Kilamu greatly expanded the audience for kuduro and built a kuduro industry while establishing the musseques as the centre of production. These producers favour the lo-fidelity DIY aesthetic that still guides much kuduro production. The third generation has again broadened the class composition of kuduristas (kuduro performers). Producers such as IVM Beatz and Hochi Fu represent a globally connected middle class with a transmedia approach to production and distribution, while performers like Os Namayer, Cabo Snoop and Titica maintain kuduro's links to the musseques. Although these categories risk glossing over diversity within each generation and downplay intergenerational crossover, they provide a fundamental chronology of social and music practices. 
These generations are each afforded respect by listeners and kuduristas of the other generations, and the evolving nature of the genre continues to be valued by listeners and artists. The first generation made kuduro at around 128-135 beats per minute (bpm) and drew heavily from influences that led to the genre's creation. These artists experimented with making a localised version of techno or house, which would fit with other music being played in local clubs. At this time, kuduro was composed on all-in-one sequencer/sampler keyboards and workstations. This equipment was brought back to Angola by middle-class youth after time spent in Europe. Many young people with the means to do so left to receive education, thus avoiding the worst of the Civil War. The sequencers had limited memory, so early productions were arrangements based on short loops. The scarcity of multi-track recording technology meant these arrangements were recorded direct to tape or CD writers without the option of overdubs. The use of vocals was limited in kuduro productions of this generation as there was a lack of studios with the capability to record vocals in Angola in the early 1990s. However, the loop-based and instrumental composition of early kuduro echoes the house and techno that had inspired early producers, so these aesthetic choices result from both technical limitations and creative decisions. For example, Tony Amado recorded his debut release in Boston, where vocal recording facilities were available, but eschewed the use of vocals until later releases. While studios in Angola were rudimentary in the mid 1990s, Rei Helder's Angola Me Leva Pais Do Futuro (1995) and Virgilio Fire's "Angola Sempre a Subir" (2001) both featured full vocal production that included international production.

Tracks of this time favoured lighter timbres than kuduro of later years. Though shaped by instrument tone, timbre incorporates and is affected by how studio processes and processors such as equalisation, reverb, amplitude and envelope are manipulated to change perceptions of rhythm, melody, harmony and mood. Meintjes contends, "feeling is crucially captured in and transported through timbre", arguing further that timbre "matters because it houses debates that are articulated as feelings about things-a "Zulu" guitar, a "ballsy" drum sound" (2003: 254). The connection that Meintjes draws between timbral characteristics and emotive qualities can be heard in the evolving soundscape of kuduro. Rather than exploring sound design possibilities offered by synthesisers, first-generation producers generally favoured synthesised reproductions of acoustic instruments, such as the horns and bass guitar sounds in Virgilio Fire's "Sempre a Subir" (2001). While the use of samples reflects the limited functionality of keyboard workstations, these representational instruments also reinforce the aesthetic of the emerging genre. Returning to "Sempre a Subir", the melody played on bass synth is a clean FM sound that imitates a fretless bass and is sculpted with equalisation to emphasise higher harmonics, giving the bass a brighter tone. This leading bass line is coupled with a rhythm section that features a kick and snare rhythm that became a feature of many kuduro productions. However, "Sempre a Subir" uses clean, dry, dynamic drum samples that have a lightness to them. These production choices add to the overall celebratory atmosphere of the track and stand out from the saturated sounds that later came to dominate the genre during the second generation. This positivity is also 
prominent in other productions of the time, including Rei Helder's "Felicidade" (Felicidade 1996). Sebem's vocal intones, "The happiness we all want! / The happiness we all felt!" over a backing track that features an upbeat riff with melodic and timbral qualities that echo early-1990s house and Eurodance acts such as Technotronic and N-Trance. The thematic and stylistic tendencies of early kuduro coincided with a scaling down of the Civil War and the emergence of a coalition government between UNITA and the MPLA.

Subsequently, the Angolan economy liberalised, and imported personal computers gradually became available to a wider section of the community. Using these computers, a number of small studios developed in the musseques, and people began to produce kuduro in a DIY capacity. By the early 2000s, many home studios were based around Fruity Loops, a pattern-based software sequencer that incorporates its own range of samples and synthesisers. The Fruity Loops interface is centred on a row of on/off controls for each sound, known as the step sequencer, that resemble the user interface of the Roland TR series of drum machines. In the default $4 / 4$ setting these 16 controls represent 4 bars of quarter notes. Drums, samples and software synthesisers are controlled using the step sequencer and, in later versions, also a digital piano roll. These loops could then be arranged and burned onto $\mathrm{CD}$ or recorded to tape. The increasing availability of computers and pirated copies of Fruity Loops began to democratise the production of kuduro. Those without their own computer could keep a copy of the software and their projects on disks or USB thumb drives and use friends' or family computers.

Though the middle class had instigated kuduro, the growing availability of music production-ready computers shifted the output of kuduro to the working class of Luanda's musseques. The movement towards the musseques and Fruity Loops resulted in some fundamental shifts in the music. The frequent use of Fruity Loops drum samples and synthesiser preset patches typify the sound of the second generation of kuduro production. Many productions feature the default drum sounds in combination with other drum samples from Fruity Loops. These samples are processed with equalisation, distortion, chorus and delay to personalise and sculpt the sound. Prior to using computers for music production, adding so many and varied effects was beyond the capabilities of most producers and studios. The increased processing power and ease of use facilitated more complex and layered beat structures, resulting in drum samples switching throughout tracks and the soon to be ubiquitous pitched tom rolls. The switch to computer-based production allowed more producers to use synthesisers, as Fruity Loops was bundled with a selection of software synthesisers. Although many producers used the preset sounds, the range of sounds possible gradually expanded the sonic palette. As producers switched to making beats in Fruity Loops, most tracks increased in tempo and were now being produced at 140 bpm. While some attribute the shift to 140 being the default tempo of the sequencer, the faster tempo also suited the increasing intensity of the music.

As kuduro was developing, vocal recordings reflected lineage to dancehall toasting and rave rap from Eurodance and hip-house, as the style had developed from live events. 


\begin{tabular}{|c|c|c|c|c|c|c|c|c|c|c|c|c|c|c|c|c|}
\hline & 1 & & & & 2 & & & & 3 & & & & 4 & & & \\
\hline hat & $\mathrm{x}$ & & $\mathrm{x}$ & $\mathrm{x}$ & $\mathrm{x}$ & & $\mathrm{x}$ & $\mathrm{x}$ & $\mathrm{x}$ & & $\mathrm{x}$ & $\mathrm{x}$ & $\mathrm{x}$ & & $\mathrm{x}$ & $\mathrm{x}$ \\
\hline snare & $\mathrm{x}$ & & & $\mathrm{x}$ & & & $\mathrm{x}$ & & $\mathrm{x}$ & & & $\mathrm{x}$ & & & $\mathrm{x}$ & \\
\hline clap & & & & $\mathrm{x}$ & & & $\mathrm{x}$ & & & & & $\mathrm{x}$ & & & & \\
\hline kick & $\mathrm{x}$ & & & & $\mathrm{x}$ & & & & $\mathrm{x}$ & & & & $\mathrm{x}$ & & & $\mathrm{x}$ \\
\hline
\end{tabular}

Figure 1. AN EXAMPLE OF ONE KUdURO RHyThM.

The rhythm and flow of Sebem's performance on "Felicidade" (Helder 1996) particularly represents this sound, utilising a percussive delivery and minimal melody. By the early 2000 s the genre had solidified and moved further away from its antecedent genres. Producers using Fruity Loops had created the archetypal kuduro rhythms (see Fig. 1) and timbres, while the vocal style had moved further from early rave and the quintessential kuduro vocal delivery emerged. The intersection between creative developments and the evolution of software and technology is evident in the changes in vocal performance in kuduro.

The vocal style of the second generation of performers such as Puto Lilas and Noite e Dia was more urgent and aggressive than those that came before them. Typically, the MC competed against the backing tracks and utilised pauses for extra effect. This newly developing sound emerged in part because of a lack of monitoring systems, in a process referred to as cantar na coluna (Alisch 2012) or "singing with the loudspeaker". Recording equipment was set up so that the instrumental track could be played back on a hi-fi speaker, with one microphone recording the output, while the vocalist used another microphone. This meant the MC had to sing loudly to overcome the speakers in the room. Over the next two years, emerging artists Tuga Agressiva, Fofando, Os Turbantes and Os Lambas developed this more distinct vocal style, harnessing the rhythmic variation and frenetic energy. Two examples demonstrate how a technique and aesthetic that emerged as a response to technological limitations outlived these limitations. In "Ngueva" (Kome Todas 2001), the vocalist can be heard delivering his rap in this style, with room reverberation prevalent on the backing track and the vocal. Os Lambas' "Se Disfio" (2005) from four years later features a similar delivery style, but with greater definition in both the backing and the vocal and no obvious room reverberation.

The popularity of Os Lambas and other acts inspired many youths to become vocalists and producers. The rapidly accelerating output of production saw kuduro become Angola's most popular music. As artists and producers came increasingly from the musseques, the residents of the musseques increasingly identified with the music and performers, which further increased participatory musical activity. As the genre became more prominent, the government moved to censor the perceived violence in the music, and repeated statements from the Ministry of Culture at the time suggested that kuduro should promote only positive messages. The Ministry's suggestion was, however, of limited success. Pointing 
to the popularity of Os Turbantes' "De Faia" (2004), Angolan cultural critic António Fernandes claims, "this was a big hit ... no radio brodcast (sic), due to the violent lyrics, no TV exposure, but everybody knew and sung the words" (Fernandes 2009). Kuduro continued to develop a broad fan base across all ages, and live performances took place everywhere, from neighbourhood dances to stadium shows in addition to national television and radio. This growing popularity in turn inspired many more youths based in the neighbourhoods to turn to production and MCing. Contemporary vocalist Dama Linda looks to this period for inspiration, suggesting that "Os Lambas renewed kuduro and showed us that kuduro could become more than what it already was". This increasingly participatory era also started to open up performance opportunities for women. Dama Linda continues, "previously there were only men and we were just lurking in from the sidelines, until my colleague Fofando exploded. When she exploded all the other women were also looking to feature. If she could do it so could we". 6

The release of version four of Fruity Loops in 2003 saw the product rebranded as FL Studio. Critically, this was the first version of the program to allow the direct recording of audio into a project. This allowed home producers and singers to record with basic equipment such as a pair of headphones plugged into the computer microphone port in place of a microphone. While the fidelity of these vocal recordings was low, this was of little concern because finished tracks were generally shared as low bitrate MP3 and played on lo-fi sound systems, such as in shared mini-bus taxis, where audiophile concerns become less relevant. This incorporation of multi-track recording into Fruity Loops led to further expansion of kuduro production, as producers including Kilamu and DJ Buda opened new studios in the musseques. As FL Studio could now perform multi-track recording, producers were able to isolate the vocal recording more effectively, which allowed the use of plug-in reverberation and delay. The use of short "slap" delays similar to those used in many hip-hop recordings can be heard in many recordings from this period. This short delay, added distortion and the acoustic imprint of the recording environments increased the energetic sound of these recordings at the expense of clarity. Some producers, such as DJ Devictor, started experimenting with extreme pitch shifting and doubling for effect, and with creating tags or sonic branding to ensure that their names were publicised along with the vocalist. However, the dominant aesthetic for vocal production at this time was for moderate processing that could be replicated in live performance.

The availability of recording-enabled computers encouraged the organisation of very localised scenes. Acts that developed their own style at neighbourhood parties recorded music for distribution predominantly within their own neighbourhoods. While locallybased identity increased the possibility of divisions between neighbourhoods, ${ }^{7}$ the use of emerging technology to strengthen community bonds reinforces Winner's assertion that "what matters is not technology itself, but the social and economic systems in which it is embedded" (Winner 1980: 20). In Angola, computers imported for business and repurposed as creative tools challenged economic structures by strengthening local cultural participation and building creative communities that served as support networks in a 
country with negligible social services and disrupted family networks. The studio as a site of social cohesion and support was common amongst musically active Luandans, with one producer suggesting that the construction of their studio was "a synonym of humanity, an act of revolution". ${ }^{8}$ The dominant methods developed and shared between users impacts on the creative output, as certain production techniques become more common than others. While many methods utilised by kuduro producers conform to the program designer's design, techniques such as deliberately overloading busses to create digital (un)musical distortion creatively misuse technology for effect. Kuduro producers used this hard, sharp, clipped distortion to reinforce notions of hardness and of surviving hard times that Young (2012) argues are important themes within kuduro. Repurposing elements within the software in this way may be considered an implicit "de-scription" (Akrich 1992: 209) of the software.

Many studios in Luanda's musseques remain somewhat rudimentary, while inconsistent electricity supplies disrupt production and can lead to hardware failure or data loss. For most, the construction of a studio is an ongoing process. Sacerdote, a member of music collective Circuito Fechado based in Luanda's Sambizanga district, recalls the initial beginnings of their studio: "I took a computer which my mother assisted me in acquiring, added some accessories to it ... I then started recording some kids on a microphone which I bought for 300 Kwanzas [AU\$3.50] and I started producing." ${ }^{9}$ For Circuito Fechado, the impetus is to have a more participatory relationship with the music, to intially record some young people from the neighbourhood and to gradually learn production. Having seen the studio in the film clip for "Falaste o Que" (Circuito Fechado 2012), I visited the studio in 2012 and saw the continuing evolution of the space as members were rendering internal walls and performing maintainence on the electrical systems. This DIY ethos is central to many studios across Luanda's musseques, as Sacerdote continues:"I wasn't bothered about the conditions or its quality and all that crap. We were just enjoying ourselves, so we just produced it according to the little resources we had". ${ }^{10}$ While the studio now has a vocal booth and space for mixing, the social aspect of the studio as a space to gather is as important to members as the effectiveness of the space acoustically and technologically. Sacerdote suggests, "the actions we take are more important than the words we speak ... I am trying to create a cultural centre, a centre where people may come to do new things". ${ }^{11}$ Through making music and other cultural activities, centres like Circuito Fechado provide spaces and support that are otherwise absent for the local community.

While the increased availability of recording technologies at the turn of the century potentially encouraged kuduro producers to develop a more explicitly critical political or cultural stance, many were not likely to be receptive to such a movement in the repressive political climate. In February 2002 the armed forces with MPLA backing killed UNITA leader Jonas Savimbi in battle. This effectively ended the armed conflict that had claimed in excess of five hundred thousand lives and displaced some four and a half million people. While the end of the Civil War may have resulted in a reduction in the level of disruption, murder and torture, these remain ever-present threats and tactics used to stifle political 
and cultural dissent. While recent pro-democracy protests and an emerging critical media provide hope that this may be changing, the reality of contemporary and past repression holds a grip over political discourse in Angola.

Accordingly, kuduro lyrics have remained predominantly apolitical, and in many cases are secondary to the beat and dance. Gracyk (1996) argues for the reduced importance of lyrics in rock music and suggests deliberate performance and production methods employed by vocalists and engineers can further mask their intentions. Similar practices can be heard in the speedy delivery and lo-fidelity aesthetic of kuduro recordings in which many vocals blend with, rather than lead, the track, the effect of which is compounded by MP3 compression. Such a reading reinforces Alisch and Siegert's assertion that "kuduro's musical and bodily-performative practices relate to real-life and media events and images and that engaging in these practices on a non-verbal level allows for negotiating topics that may otherwise be impossible to discuss" (Alisch and Siegert 2012: 52). The authors argue that, through music and dance, kuduro participants negotiate challenges faced in daily social, political and working life that cannot be expressed in words.

More recently, producers from middle-class families have turned back to kuduro production. Performers have adopted elements of a wider range of genres and developed working methods to incorporate new studio technologies. Two of the styles drawn into kuduro from 2008 are n'dombolo and Afrohouse. N'dombolo is a Congolese style of music and dance that emerged at the same time as kuduro. N'dombolo shares some stylistic similarities with kuduro in the rhythm and vocal delivery but is performed at slower tempos than contemporary kuduro, at around $125 \mathrm{bpm}$. N'dombolo also features greater emphasis on melody and widespread use of non-synthesised instruments, particularly guitar. The inclusion of such instrumentation into kuduro was facilitated by increased international trade that re-introduced instruments, including the guitar, that had been absent from the Angolan musical landscape for much of the previous thirty years. Furthermore, the influence of n'dombolo reflects contemporary social and cultural politics, as a large population of Congolese asylum seekers resided in Angola, while a large population of Angolan refugees lived in the Democratic Republic of Congo. The most widespread influence of n'dombolo occurred from 2009 through to 2011 as tens of thousands of Congolese in Angola suffered human rights abuses and were expelled from the country. While a number of artists incorporated N'dombolo, its influence was to be short lived. The n'dombolo-infused hooks on "Kusi De Pole" and "Essa é a TKNY" from Titica's 2011 album Chão were two of the most popular tracks to incorporate n'dombolo, but also signalled a decline in the genre's influence.

The adoption of traits of Afrohouse is more widespread, and has the potential for longer lasting influence. Afrohouse bears many stylistic similarities with more established forms of house, but draws particularly from deep South African house. Afrohouse features prominent bass lines, regional instrumentation, the sparse use of vocals, and ranges from 120 to $130 \mathrm{bpm}$. Afrohouse tends to have clean production with distinct bands of sound, minimal distortion and a greater emphasis on space, through the arrangement and use of 
reverbs. The productions of Luanda-based Powerhouse Entertainment particularly reflect the melding of Afrohouse and kuduro. In Cabo Snoop's "Windeck" (2010), producer IVM Beatz utilises a slower tempo of $130 \mathrm{bpm}$ and strips back the beat. This modified kuduro beat is paired with minimal lead and bass lines that swell around the beat. The spacious arrangement and clean production in "Windeck" is typical of Afrohouse and lacks the overdriven distorted aesthetic of much kuduro. Snoop uses his voice minimally and rhythmically to create off beats and cross rhythms, performing full lines of lyrics only during breakdowns, in which the beat has dropped out.

For some producers, the use of Afrohouse elements has accompanied a shift away from loop-based FL Studio to sequence-based software, such as Cubase and Logic Pro. While recent versions of FL Studio have the option to compose drums in a sequencer layout similar to other software packages, many producers continue to use the step sequencer to attain the rigidly quantised beats common to kuduro, and utilise volume automation to create a perception of swing. The more advanced sampler and MIDI implementation found in Logic Pro favour music that features micro-rhythmic manipulation, and effects that evolve over longer periods, as is more common in Afrohouse. I visited the studio of producer and DJ Guerito in 2012 shortly after his releases with Os Lambas and Bruno M as he was in the process of switching software platforms from FL Studio to Logic Pro and expanding his repertoire. He suggested that to develop in Angola's evolving music industry, he "had to firstly professionalize myself with some recent software, basically play all genres although they are mostly focused on Afrohouse and most of the electronic genres without singing". ${ }^{12}$ For Guerito and other producers, such changes need to be balanced, "I already have a good reputation in terms of kuduro, so I would not like to do anything that might mess my good reputation". ${ }^{13}$

\section{CONCLUSION}

The generations of Angolan youth that experimented first with making techno, and later developing and frequently reimagining kuduro, have been crucial to the development of collective identity in a nation that is young, urban, fractured and healing. Though freedom of expression is curtailed in Angola, kuduro has created a space and performative languages for discussing the concerns of youth in a nation where over sixty percent of the population is under twenty-five years old. These languages take the form of musical signifiers, aesthetic developments and dance moves that can be heard and seen in the hard drumbeats, distorted rapping and hyper-athleticism central to kuduro. Kuduro's producers have used music technologies as media for self-expression, and to reflect collective narratives, as the music has become a site for the representation and negotiation of identity.

As kuduro has developed and the political atmosphere has shifted from hope for a warfree egalitarian Angola to a realisation that the political and economic conditions for most Angolans would see little improvement, the aesthetic of the music has grown harder and more timbrally distorted. Studio and performance practices that have emerged within 
kuduro are embedded with social and economic conditions of groups that have made and listened to kuduro, including the working- and middle-class Angolans and immigrant communities. The relationship between composer, technology and message can be heard in the evolving sounds, technologies and lyrics of kuduro, as the centre of production shifted from middle-class inner-Luandan producers to the residents of the musseques and back. While reflecting and challenging local and national social hierarchies, the evolving aesthetics of kuduro respond also to artistic impulse and bridge the communities that make, perform, listen and dance to the music.

\section{ACKNOWLEDGMENTS}

Thanks to Frederick Moehn, Stefanie Alisch, Paula Santana, Sotero Caio, Jó Kindanje, Sérgio Guerra, Sacerdote and Dog Murras for their help in Angola. Thanks also to Ananya Kabir and Kipps Horn. Lastly, thanks to Benjamin Lebrave for his relentless work at Akwaaba music and elsewhere.

\section{NOTES}

1 MC Sacerdote, interview with the author (Sambizanga, Angola), 28 May 2012.

2 While the terms "middle class" and "working class" will be used throughout this article, I recognise that a range of factors further complicate notions of social class in Angola. These forces include the dominance of an intergenerational elite politico-military class, rapid mass urbanisation, recent transition to a market economy, a large informal economy and widespread structural unemployment. My own usage of these terms situates the residents of the musseques, whether employed in the city, in the informal economy or unemployed, as working class, and those living downtown or in recently established outer urban estates as middle class. For further discussion of the developing nature of class in Angola, see Rodrigues 2007.

3 Lusotropicalismo is a reading of Portuguese colonialism developed by Gilberto Freyre. Freyre argues that the nature of Portuguese colonialism was more humane and adaptable than other colonial powers due to Portugal's history as a colonised nation, the tropical climate and geographical proximity to Africa. For further discussion of Lusotropicalismo, see Freyere (1964).

4 This meta-genre includes a range of genres such as kwaito and tecno brega that developed in the global South and are typified by the use of elements of North American and European electronic music with local influences, mediated through technology.

5 Dama Linda, interview with the author (Sambizanga, Angola), 01 May 2012.

6 Dama Linda, interview with the author (Sambizanga, Angola), 01 May 2012.

7 Antagonism between Os Lambas from Sambizanga and Os Vagabanda of Rangel is a notable example, with the dispute being featured in a number of feature films including Assoltos em Luanda (2007).

8 MC Sacerdote, interview with the author (Sambizanga, Angola), 28 May 2012.

9 MC Sacerdote, interview with the author (Sambizanga, Angola), 28 May 2012.

10 MC Sacerdote, interview with the author (Sambizanga, Angola), 28 May 2012. 
11 MC Sacerdote, interview with the author (Sambizanga, Angola), 28 May 2012.

12 Guerito, interview with the author (Combatentes, Angola), 30 May 2012.

13 Guerito, interview with the author (Combatentes, Angola), 30 May 2012.

\section{REFERENCES}

Akrich, Madeline. 1992. “The De-scription of Technical Objects”. In Shaping Technology Building Society, ed. W. Bijker and J. Law, 205-24 Cambridge: MIT.

Alisch, Stefanie and Siegert, Nadine. 2011. "Angolanidade Revisited - Kuduro". Norient. 6 June $<$ http://norient.com/en/academic/kuduro> (accessed 30 April 2014).

Alisch, Stefanie. 2012. “Technology of Kuduro”. Os Kuduristas. $<$ http://oskuduristas.com/en/ posts/8> (accessed 31 August 2013).

Alisch, Stefanie and Siegert, Nadine. 2013. "Grooving on Broken: Dancing War and Trauma in Angolan Kuduro". In Art and Trauma in Africa: Representations of Reconciliation in Music, Visual Arts, Literature and Film, ed. Lizelle Bisschoff and Stefanie Van de Peer, 50-68. London: I.B. Tauris \& Co.

Brown, Jayna. 2010. "Buzz and Rumble: Global Pop Music and Utopian Impulse". Social Text 28(1): 125-46. <http://dx.doi.org/10.1215/01642472-2009-063>.

Butler, Mark. 2006. Unlocking the Groove: Rhythm, Meter and Musical Design in Electronic Dance Music. Bloomington: Indiana University.

dos Santos, José Eduardo Paulino. 2012. "Kuduro". Nacional Cine-Teatro (Luanda): Conferência Internacional sobre Kuduro

Fernandes, António. 2009. "Defaya by Os Turbantes”. Kuduro de Angola. 16 September. < http:// kuduro.podomatic.com/entry/2009-09-16T14_15 11-07_00> (accessed 03 March 2011).

Freyre, Gilberto. 1964. The Masters And The Slaves: A Study In The Development Of Brazilian Civilization. Berkeley: University of California.

Gracyk, Theodore. 1996. Rhythm and Noise: An Aesthetics of Rock. New York: I.B Taurus.

Krug, Jessica. 2011. “The Strange Life of Lusotropicalism in Luanda: On Race, Gender and Sexuality in Angola”. In Black Subjects in Africa and Its Diasporas: Race and Gender in Research and Writing, ed. Benjami Talton and Quincy T Mills, 109-29. New York: Palgrave Macmillan.

Madrid, Alejandro. 2008. Nor-Tec Rifa: Electronic Dance Music from Tijuana to the World. New York: Oxford University.

Meintjes, Louise. 2003. The Sound of Africa: Making Zulu Music in a South African Studio. Durham: Duke University.

Montano, Ed. 2010. “'How do you know he's not playing Pac-Man while he's supposed to be DJing?"”. Technology, Formats and the Digital Future of DJ Culture”. Popular Music 29(3): 397-416. < http://dx.doi.org/10.1017/S0261143010000449>

Moorman, Marissa. 2008a. Intonations: A Social History of Music and Nation in Luanda, Angola, from 1945 to Recent Times. Athens: Ohio University.

Moorman, Marissa. 2008b. “Estámos Sempre a Subir’: kuduro music in Angola and Portugal” University of Notre Dame (Notre Dame) Africa in Portuguese, the Portuguese in Africa: 
An International Research Conference. < http://kellogg.nd.edu/projects/FLAD/pdfs/ Moorman,\%20Marissa.pdf $>$ (accessed 02 March 2013).

Rivera, Raquel et al. 2009. Reggaeton. London: Duke University.

Rodrigues, Cristina. 2007. "From Family Solidarity to Social Classes: Urban Stratification in Angola (Luanda and Ondjiva)". Journal of Southern African Studies 33(2): 235-50. < http:// dx.doi.org/10.1080/03057070701292566>

Sicko, Dan. 2010. Techno Rebels. Michigan: Painted Turtle Books.

Steingo, Gavin. 2005. "South African Music After Apartheid: Kwaito, the 'Party Politic', and the Appropriation of Gold as a Sign of Success". Popular Music and Society 28(3):333-58. <http://dx.doi.org/10.1080/03007760500105172>

Tjora, Aksel. 2009. “The Groove in the Box: A Technologically Mediated Inspiration in Electronic Dance Music". Popular Music 28(2): 161-77.

Tvedten, Inge. 1998. Angola: Struggle for Peace and Reconstruction. Boulder: Westview.

Wicke, Peter. 1990. Rock Music: Culture, Aesthetics and Sociology. Cambridge: Cambridge University.

Winner, Langdon. 1980. “Do Artifacts Have Politics?” Daedalus 109(1): 121-36. < http://dx.doi.org/10.2307/20024652>

\section{DISCOGRAPHY}

Cabo Snoop. 2010. Bluetooth. Powerhouse Entertainment (CD). <http://www.youtube.com/watch?v=hcJr-3XDx5s > (accessed 03 February 2014).

Circuito Fechado. 2012. "Falaste O Que”. Circuito Fechado (MP3). $<$ http://www.youtube.com/watch?v=M110x-d3xgc > (accessed 03 February 2014).

Helder Rei do Kuduro. 1995. Angola Me Leva Pais Do Futuro. Sons d'Africa (CD Reissue).

Helder Rei do Kuduro. 1996. Felicidade Se Bem. Sons d'Africa (CD Reissue). $<$ http://www.youtube.com/watch?v=yAA3dfHlmwU > (accessed 03 February 2014).

Kome Todas. 2001. "Ngueva”. (MP3). $<$ http://www.youtube.com/watch?v=QK0mb1i-rB44 $>$ (accessed 03 February 2014).

Os Lambas. 2005. "Se Disfio”. (MP3). $<$ http://www.youtube.com/watch?v=vGiRHHCxL90 $>$ (accessed 03 February 2014).

Os Turbantes. 2004. "De Faia”. (MP3). <http://www.youtube.com/watch?v=ugIkC49j1xk> (accessed 03 February 2014).

Power Boyz. 2012. “Tchuna Baby”. Powerhouse Entertainment (CD). $<$ http://www.youtube.com/watch?v=odB5LSOvdmk > (accessed 03 February 2014).

Titica. 2012. Chão. LS Produções (CD). <http://www.discogs.com/Titica-Ch\%C3\%A3o/release/4039786>

Virgilio Fire. 2001. Projecto da Banda. Vidisco (CD Reissue). <http://www.amazon.com/Angola-Sempre-a-Subir/dp/B007U2JQME>

\section{FILMOGRAPHY}

Narciso, Henrique. 2007. Assoltos em Luanda. 